\title{
Cellular compatibility of nanocomposite scaffolds based on hydroxyapatite entrapped in cellulose network for bone repair
}

\author{
Faranak Beladi $^{1}$, Samaneh Saber-Samandari ${ }^{2 *}$, Saeed Saber-Samandari $^{3 *}$ \\ ${ }^{1}$ Material and Biomaterial Research Center, Tehran, Iran \\ ${ }^{2}$ Department of Chemistry, Eastern Mediterranean University, Gazimagusa, TRNC via Mersin 10, Turkey \\ ${ }^{3}$ New Technologies Research Center, Amirkabir University of Technology, Tehran, Iran
}

*Corresponding Authors:

Dr. Samaneh Saber-Samandari, (Tel: +90 392630 2004, Email: samaneh.saber@ gmail.com)

Dr. Saeed Saber-Samandari (Tel: +98 216454 5193, Email: saeedss@aut.ac.ir) 


\begin{abstract}
In the past few decades, artificial graft materials for bone tissue engineering have gained much importance. The purpose of this research is to develop and characterize a novel 3D nanocomposite scaffold that closely mimics the properties of real bone, such as morphology, composition, and mechanical characteristics. This novel porous 3D nanocomposite scaffold is composed of polyacrylamide grafted cellulose, and hydroxyapatite. The morphology, structure, and mechanical properties of cellulose-graft-polyacrylamide containing different amounts of nano-hydroxyapatite were characterized. The swelling behavior of the scaffolds was examined in both water and phosphate buffer saline (PBS) solution. The cytotoxicity of the scaffolds was determined by MTT assays on human fibroblast gum (HuGu) cells. Results showed that the nanocomposite scaffolds were highly porous with maximum porosity of $85.7 \%$ interconnected with a pore size of around $72-125 \mu \mathrm{m}$. The results of cell culture experiments showed that the scaffold extracts do not have cytotoxicity in any concentration. Our results suggested that the introduced scaffolds are comparable with the trabecular bone from the compositional, structural, and mechanical perspectives and have a great potential to be used as bone substitute.
\end{abstract}

Keywords: Bone tissue engineering; Cellulose; Hydroxyapatite; Nanocomposite 


\section{Introduction}

Bone repair is a major issue in maxillofacial orthopedic surgery because of various bone diseases, such as bone infections, bone tumors, skeletal abnormalities, and bone loss by trauma ${ }^{1}$. The traditional treatments for bone defects include autografts, allografts, and xenografts. Although autografts are well suited for bone regeneration, they have to be dissected from bone tissue from another site. This process not only causes donor site morbidity but also difficulty in constructing a graft of the desired shape using the dissected tissue ${ }^{2,3}$. Moreover, pathogen transfer or immune reaction to allografting and xenografting is a possibility ${ }^{4,5}$. To overcome the above-mentioned drawbacks, the fabrication of an ideal synthetic bone graft has been devoted to bone tissue engineering, in which a 3D porous scaffold of ceramic (i.e., calcium phosphate) ${ }^{6}$, synthetic polymers (i.e., PVA, PCL, and PLGA) ${ }^{7-9}$, natural polymers (i.e., chitosan, gelatin, and cellulose) ${ }^{10-12}$, or their composites ${ }^{13-15}$ is used to mimic the natural bone behavior to some extent.

As an interesting biomaterial with potential orthopedic and dental applications hydroxyapatite (HA) has good mechanical properties ${ }^{16}$, osteoconductivity ${ }^{17}$, bioactivity ${ }^{18}$, and bone bonding ability ${ }^{19}$. HA is not biodegradable and can be removed and remodeled in the host. If implanted directly, it may dislocate within the tissue ${ }^{20}$. To eliminate such an undesired mobility, HA is usually mixed with natural or synthetic polymers, such as cellulose (Cel) and polyacrylamide (PAAm) ${ }^{21-24}$. Cel is the most abundant material in most plants and bacteria. It degrades slowly because of the absence of enzymes that attack the linkage. Cel is also a promising material for biomedical applications, including drug delivery and tissue engineering, because of its biocompatibility, non-toxicity, reactive surfaces for protein binding, biodegradability, readily 
modified properties, and mechanical strength and resistance to breakdown in vivo ${ }^{25}$. However, only a few studies have been conducted on the application of Cel as a scaffold for cell culturing because of the absence of an intrinsic 3D architecture. Further, Cel has some other drawbacks such as low mechanical properties. As a result, the use of another synthetic or natural polymer may provide additional 3D architecture for Cel based scaffolds. PAAm is a synthesized polymer used in biomedical engineering and tissue engineering ${ }^{26-29}$ because of its non-toxic and biologically inertness, capacity for preserving its shape and mechanical strength, and convenient adjustability of mechanical, chemical, and biophysical properties ${ }^{30,31}$. However, brittleness as its poor mechanical property caused by the lack of an efficient energy dissipation mechanism and the irregular distribution of cross-linking points have limited further research on using PAAm solely ${ }^{32,33}$.

The work aimed to develop and characterize a new 3D nanocomposite scaffold made of Cel, PAAm, and nanopowders of HA (n-HA) for use in bone repair applications to solve the abovementioned shortcomings. To this end, hydroxyapatite/cellulose-graft-polyacrylamide (HA/Cel-gPAAm) nanocomposite scaffolds were synthesized by freeze-drying method. The morphology and structural characteristics were observed by scanning electron microscopy (SEM), Fourier transform infrared spectroscopy (FTIR), energy-dispersive X-ray spectroscopy (EDX), and Xray diffraction analysis (XRD). The biocompatibility of the scaffolds was tested by culturing HuGu cells in vitro. The mechanical properties of the scaffolds were measured by tensile test instrument. The swelling behavior of the scaffolds was examined in both water and phosphate buffer saline (PBS) solution. To our knowledge, this study is the first on the HA/Cel-g-PAAm composite for 3D scaffolds. 


\section{Materials and methods}

\subsection{Materials}

Microcrystalline cellulose extracted from cotton linters with $20 \mu \mathrm{m}$ particle size and 0.5 g.L ${ }^{-1}$ bulk density (reported by the manufacturer, Aldrich) was used as a basic of composite construction. The cellulose was dissolved in a $5 \% \mathrm{w} / \mathrm{v}$ mixture of dimethylformamide and lithium chloride (TAT, Iran). n-HA (CAM implants, Netherlands), potassium persulfate (BDH Chemicals, UK) as an initiator, acrylamide (Merck) as a monomer, and N,N'-methylene-bisacrylamide (Aldrich) as a crosslinker were applied. Sodium chloride, potassium chloride, sodium hydrogen phosphate, and di-potassium hydrogen phosphate were used as received (TAT, Iran) for the preparation of PBS solution.

\subsection{Synthesis of nanocomposite scaffolds}

In this study, the nanocomposite scaffolds were prepared using the prepared HA/Cel-g-PAAm nanocomposite powders, which were synthetized through free radical polymerization. First, Cel $(0.8 \mathrm{~g})$ was dissolved in a mixture of lithium chloride ( $3 \mathrm{~g})$ and dimethylformamide solution (60 $\mathrm{mL}$ ) and stirred at $70{ }^{\circ} \mathrm{C}$ in a flask fitted to an argon gas inlet. After complete dissolving of Cel, potassium persulfate $(0.06 \mathrm{~g})$ was added to the Cel solution. Third, acrylamide $(1.2 \mathrm{~g}), \mathrm{N}, \mathrm{N}$ 'methylene-bis-acrylamide (0.03 g), and different amounts of n-HA were added gently into the initiated Cel solution, and the solution was stirred under argon gas at $68{ }^{\circ} \mathrm{C}$. After $3 \mathrm{~h}$ and complete graft polymerization of acrylamide onto Cel, the prepared nanocomposite powder was dispersed in distilled water many times to remove unreacted monomer, initiator, and solvent. Finally, the prepared nanocomposite powders were vacuum-filtered and dried at $50{ }^{\circ} \mathrm{C}$ in an oven overnight. Using this method, five different nanocomposite powders containing $0.18,0.36$, 
$0.54,0.72$, and $0.90 \mathrm{~g}$ of $\mathrm{n}-\mathrm{HA}$, namely, $\mathrm{H} 1, \mathrm{H} 2, \mathrm{H} 3, \mathrm{H} 4$, and $\mathrm{H} 5$, respectively were synthesized. To prepare the scaffolds, $0.1 \mathrm{~g}$ of HA/Cel-g-PAAm nanocomposite powders was dispersed in a diluted acetic acid solution (4\%) and stirred at room temperature for $72 \mathrm{~h}$. After sonication for $90 \mathrm{~s}$, the solutions were placed into plastic molds and kept in a freezer at $-20^{\circ} \mathrm{C}$ for $24 \mathrm{~h}$. Finally, the solidified mixtures were transferred into a lyophilizer (FD-10, Pishtaz Engineering Co., IRAN) and then freezed up to $-56{ }^{\circ} \mathrm{C}$ (vacuum 6.2 mbar) for $8 \mathrm{~h}$ and then warmed to $-5{ }^{\circ} \mathrm{C}(1.4$ mbar) for $6 \mathrm{~h}$ and to $24{ }^{\circ} \mathrm{C}(0.98 \mathrm{mbar}$ ) for 2 days in the main drying phase (see Scheme 1$)$.

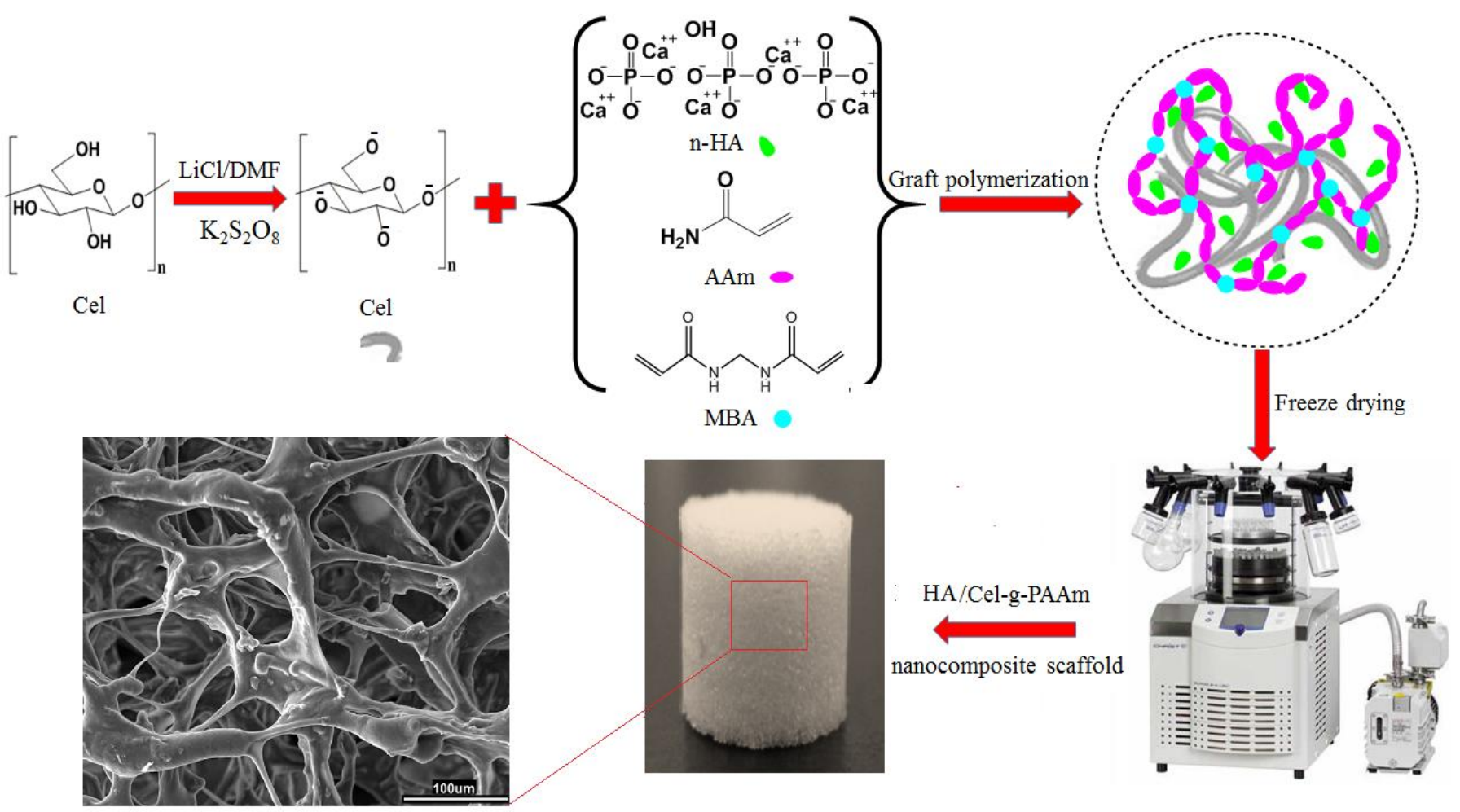

Scheme 1

\subsection{Characterization of the prepared scaffolds}

The synthesis of HA/Cel-g-PAAm nanocomposite powders was verified by a FTIR spectrophotometer (Perkin-Elmer 8700, Japan) in the range of $400-4000 \mathrm{~cm}^{-1}$. The major phases 
of the scaffolds were analyzed using X-rays diffractometer (EQuniox 300, France) using $\mathrm{Cu}-\mathrm{K} \alpha$ radiation $(1.54 \AA)$ at a $2 \theta$ range of $10-70^{\circ}$ with voltage and current settings of $40 \mathrm{kV}$ and $30 \mathrm{~mA}$, respectively. The morphology and chemical composition of the prepared scaffolds were characterized using SEM-EDS (Tescan Vega 3 LMU with Bruker Quantax EDS, Czech Republic). The mechanical properties of the prepared scaffolds were tested by SANTAM compression test apparatus (ASTM D5024-95, Iran) at a loading rate of $0.5 \mathrm{~mm} / \mathrm{min}$ using the circular shape scaffolds with dimensions $5 \mathrm{~mm}$ diameter and $10 \mathrm{~mm}$ height. The elastic modulus and compressive strength of the scaffolds among the other mechanical properties were selected to be calculated using the stress-strain curve. The elastic modulus is the slope of the initial linear portion, and the compressive strength is the maximum point of the curve.

\subsection{Porosity determination of the scaffolds}

The apparent porosity percentage of the prepared nanocomposite scaffolds was determined through liquid displacement method ${ }^{34}$. At first, the scaffolds were placed in a graduated cylinder of water and kept under water to fill the pores of scaffolds. Then, the filled pore scaffolds were removed from water. The porosity $(\%)$ of the prepared scaffolds were calculated using the following equation:

porosity $(\%)=\frac{\mathrm{V}_{1}-\mathrm{V}_{3}}{\mathrm{~V}_{2}-\mathrm{V}_{3}} \times 100$

Where $V_{1}$ is initial volume of water before immersion of the scaffold, $V_{2}$ is volume of water after immersion of the scaffold and $\mathrm{V}_{3}$ is final volume of water after removing of filled pores scaffold. In addition, the pore size of the prepared scaffolds in 10 different cross-sectional SEM micrographs representing different regions of the scaffold was calculated using ImageJ software. The dimensions of more than 50 pores were measured and averaged to obtain a mean pore size. 


\subsection{Swelling behavior of the prepared scaffolds}

The swelling behavior and the structural stability of scaffolds are critical to their practical use in tissue engineering ${ }^{35}$. The swelling properties of the synthesized nanocomposite scaffolds were evaluated in water and PBS solution. The dried pieces of the prepared nanocomposite scaffolds were weighed and immersed in water and PBS solution. The scaffolds began to soak and imprison liquids in their macropores for a time period until equilibrium was reached. At the equilibrium stage with further increases in time, large differences in the swelling percentage of the scaffolds were not observed. The swollen nanocomposite scaffolds were blotted and weighed after removing excess water on their surface. The swelling percentage was determined using the following equation ${ }^{36}$ :

Swelling $(\%)=\frac{\mathrm{w}_{\mathrm{s}}-\mathrm{w}_{\mathrm{d}}}{\mathrm{w}_{\mathrm{d}}} \times 100$

Where $\mathrm{W}_{\mathrm{s}}$ and $\mathrm{W}_{\mathrm{d}}$ are the weights of the swollen and the dried scaffolds, respectively.

Note that the PBS solution was prepared by dissolving four salts, namely, $\mathrm{NaCl}(8 \mathrm{~g}), \mathrm{KCl}(0.2$ g), $\mathrm{Na}_{2} \mathrm{HPO}_{4}(1.44 \mathrm{~g})$, and $\mathrm{KH}_{2} \mathrm{PO}_{4}(0.24 \mathrm{~g})$, in distilled water $(800 \mathrm{~mL})$. After adjusting the $\mathrm{pH}$ of the solution to 7.4 with $\mathrm{HCl}\left(1 \mathrm{~mol} . \mathrm{L}^{-1}\right)$, the total volume of the solution reached $1 \mathrm{~L}$.

\subsection{Cytotoxicity evaluation of the prepared scaffolds}

Human gum fibroblast cells $(\mathrm{HuGu})$ from the Iranian Biological Resources Center (IBRC) were cultured in Duelbacco's Minimum Eagle's Medium (DMEM) supplemented with 2 mmol.L ${ }^{-1}$ glutamine and $10 \%$ fetal bovine serum (FBS) and maintained in an $5 \% \mathrm{CO}_{2}$ incubator at $37{ }^{\circ} \mathrm{C}$. When the cells reached the stage of confluence, they were harvested by trypsinization and were added a fresh culture medium to create a cell suspension. The 3-(4,5-dimethylthiazol-2-yl)-2,5- 
diphenyltetrazolium-bromide (MTT, Aldrich) assay, which was based on the extraction method, was applied to evaluate the cytotoxic effect of the prepared scaffolds. A cell suspension with a concentration of 5000 cells in $100 \mu \mathrm{L}$ of medium was loaded into the well of a 96-well flatbottom culture plate and incubated at $37{ }^{\circ} \mathrm{C}$ in an incubator. After seeding of the fibroblast cells, they were treated with seven different concentrations of H1 and H5 scaffold extracts (0.03-2.00 $\left.\mathrm{mg} \cdot \mathrm{mL}^{-1}\right)$. After different incubation times $(24,48$, and $72 \mathrm{~h}$ ) and the aspiration of the medium, $20 \mu \mathrm{L}$ of MTT solution (5 mg.mL $\mathrm{m}^{-1}$ of PBS) was added to each well, and then incubation was conducted at $37^{\circ} \mathrm{C}$ for $4 \mathrm{~h}$. The upper solvent was removed, and $200 \mu \mathrm{L}$ of dimethyl sulfoxide (DMSO) was added to dissolve the precipitated formazan crystals for $6 \mathrm{~h}$ at $37^{\circ} \mathrm{C}$. Three parallel replicates were analyzed for each sample. The controls (empty wells without scaffolds extracts) were treated in the same manner. Finally, the plate cover was removed, and the optical density (OD) values were recorded at $570 \mathrm{~nm}$ by the absorbance microplate reader (Bio-Tek, ELx-800, USA). The cell viability was calculated according the following equation ${ }^{37}$ :

Cell viability $(\%)=\frac{\mathrm{OD} \text { sample }}{\mathrm{OD} \text { Control }} * 100$

\section{Results and Discussion}

\subsection{Characterizations of the prepared scaffolds}

\subsubsection{Fourier transforms infrared (FTIR) analysis}

To confirm the graft polymerization of acrylamide onto Cel and to show the presence of various n-HA amounts, the FTIR spectra of the prepared nanocomposite scaffolds were investigated (Figure 1). In the spectra of all samples, the broad peak in the $896-1235 \mathrm{~cm}^{-1}$ wavenumber range was related to the pyranoid ring of the Cel. The strongest and broadest peak associated with the asymmetric C-O-C bridge stretching of the Cel ring was observed at approximately $1082 \mathrm{~cm}^{-1}$ in 
the spectra of all samples. In addition, the broad absorption peak between $3,000 \mathrm{~cm}^{-1}$ and 3,700 $\mathrm{cm}^{-1}$ belongs to the stretching vibration of the hydroxyl groups of Cel and n-HA observed. The absorption band at $1,650 \mathrm{~cm}^{-1}$ attributed to the stretching vibration of $\mathrm{C}=\mathrm{O}$ bonds in PAAm confirmed the graft polymerization of PAAm onto Cel. The modifications that occured during the interaction of n-HA with Cel-g-PAAm can be confirmed by the presence of three absorption bands at $1092 \mathrm{~cm}^{-1}, 1029 \mathrm{~cm}^{-1}$ and $961 \mathrm{~cm}^{-1}$, which correspond to the symmetric and asymmetric stretching modes of phosphate groups $\left(\mathrm{PO}_{4}{ }^{3-}\right)$ in n-HA ${ }^{38}$. The absorption peaks were from 566 $\mathrm{cm}^{-1}$ to $633 \mathrm{~cm}^{-1}$ and were assigned to the asymmetric bending modes of the O-P-O bonds of the phosphate groups in n-HA ${ }^{39}$. The intensity of the peaks assigned to n-HA was improved by increasing the amounts of n-HA in the prepared scaffolds (H5> H4> H3> H2> H1). These supportive results confirmed the graft polymerization of AAm onto Cel and the synthesis of Celg-PAAm-based nanocomposites with different n-HA contents. 


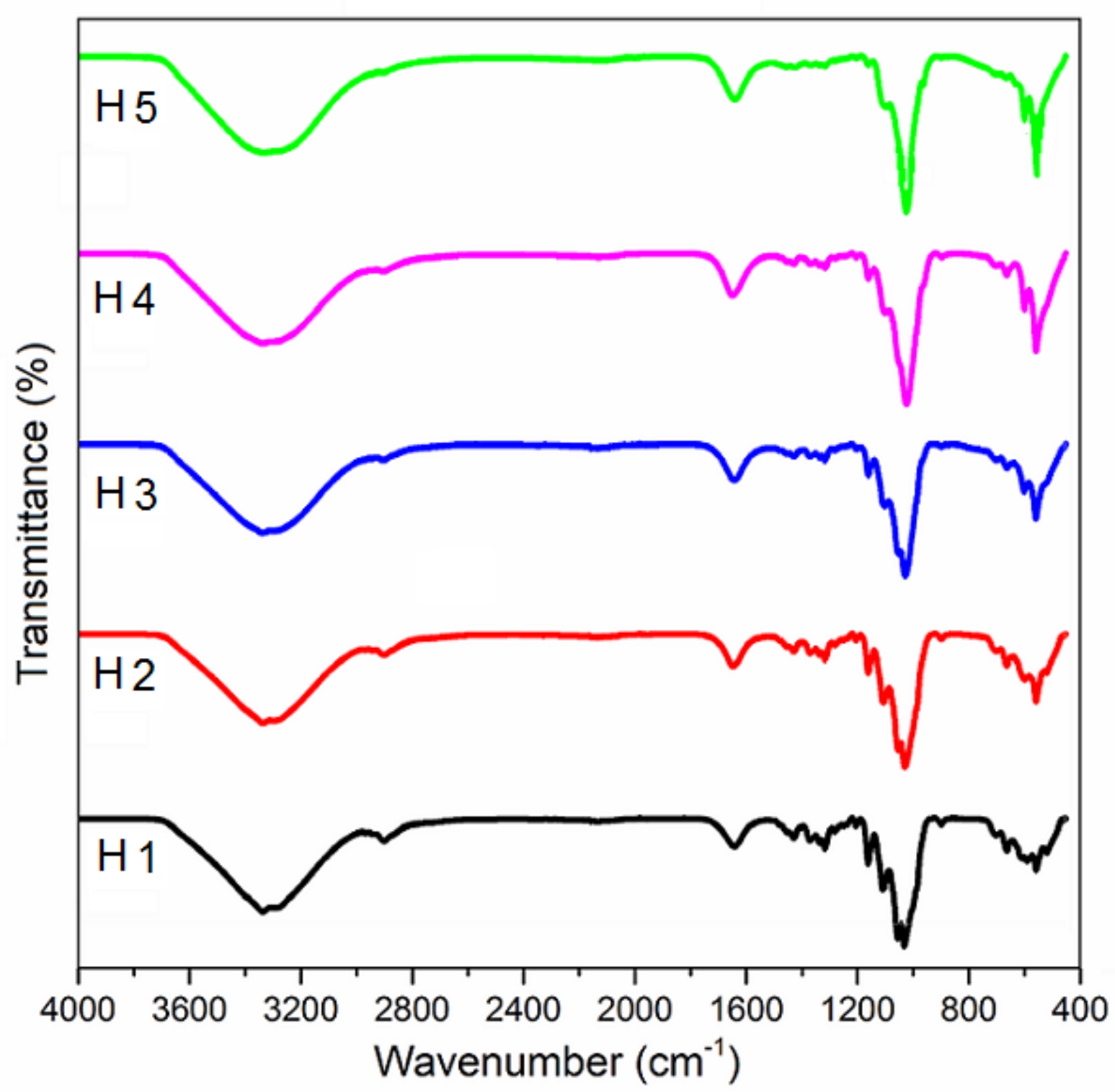

Figure 1

\subsubsection{X-ray diffraction (XRD) analysis}

Figure 2 shows the XRD patterns of the synthesized nanocomposite scaffolds. For all of the samples, the crystalline peaks observed at approximately $23.2^{\circ}, 26^{\circ}, 29.3^{\circ}, 32.2^{\circ}, 46.6^{\circ}$, and $49.4^{\circ}$ confirmed the presence of n-HA in the scaffold structure ${ }^{40}$. As shown in Figure 2, the intensity of the mentioned peaks clearly increased by the increase in the amounts of n-HA in 
samples H1 to H5. Furthermore, a diffraction peak was detected at $2 \theta=16^{\circ}$, which was assigned to the reflection of Cel-g-PAAm.

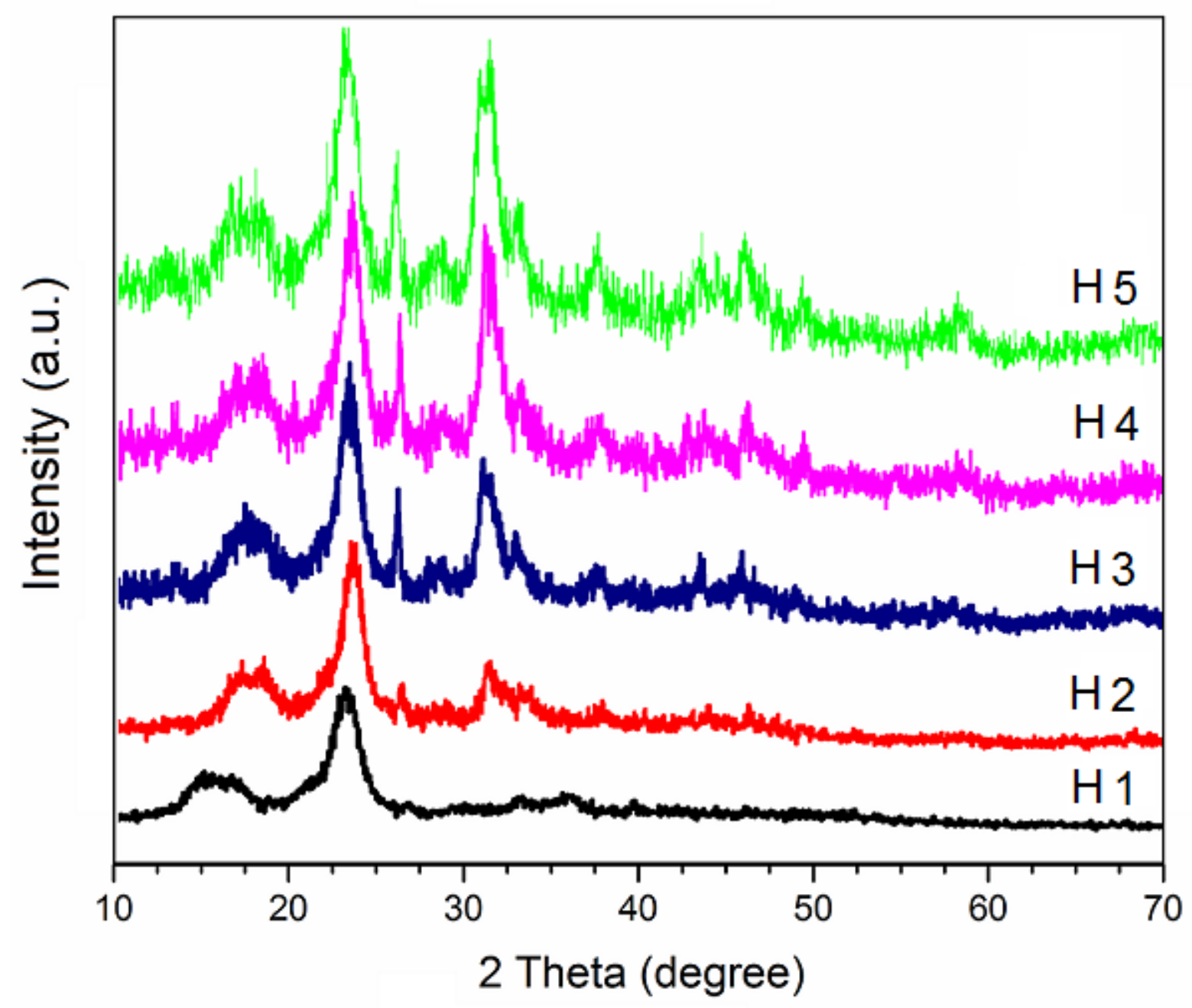

Figure 2

\subsubsection{Scanning electron microscopy (SEM) and energy-dispersive X-ray (EDS) analysis}

SEM images of the prepared nanocomposite scaffolds are shown in Figure 3. All the scaffolds had irregular interconnected pores. These sub-micro pores created a rough texture on the sample surface, which is essential for cell attachment and proliferation. The average sizes of these pores are listed in Table 1. The size was in the range of $72-125 \mu \mathrm{m}$, which is appropriate for the 
vascularization process in tissue engineering applications. In addition, the maximum porosity percentage was calculated $85.7 \%$ for the $\mathrm{H} 5$ scaffold. As shown in Table 1, increasing the amount of n-HA in the composition of the scaffolds from $\mathrm{H} 1$ to $\mathrm{H} 5$ led to the increase in the porosity percentage, but it decreased the pore size of the scaffolds because of the increase in crystallinity of the prepared nanocomposite scaffolds. Manicini et al. found that the porosity of the scaffolds increased with the increase in crystallinity ${ }^{41}$. The results show that the prepared scaffolds are similar in appearance to the cancellous bone with $75 \%-85 \%$ porosity and 300-600 $\mu \mathrm{m}$ diameter size. 

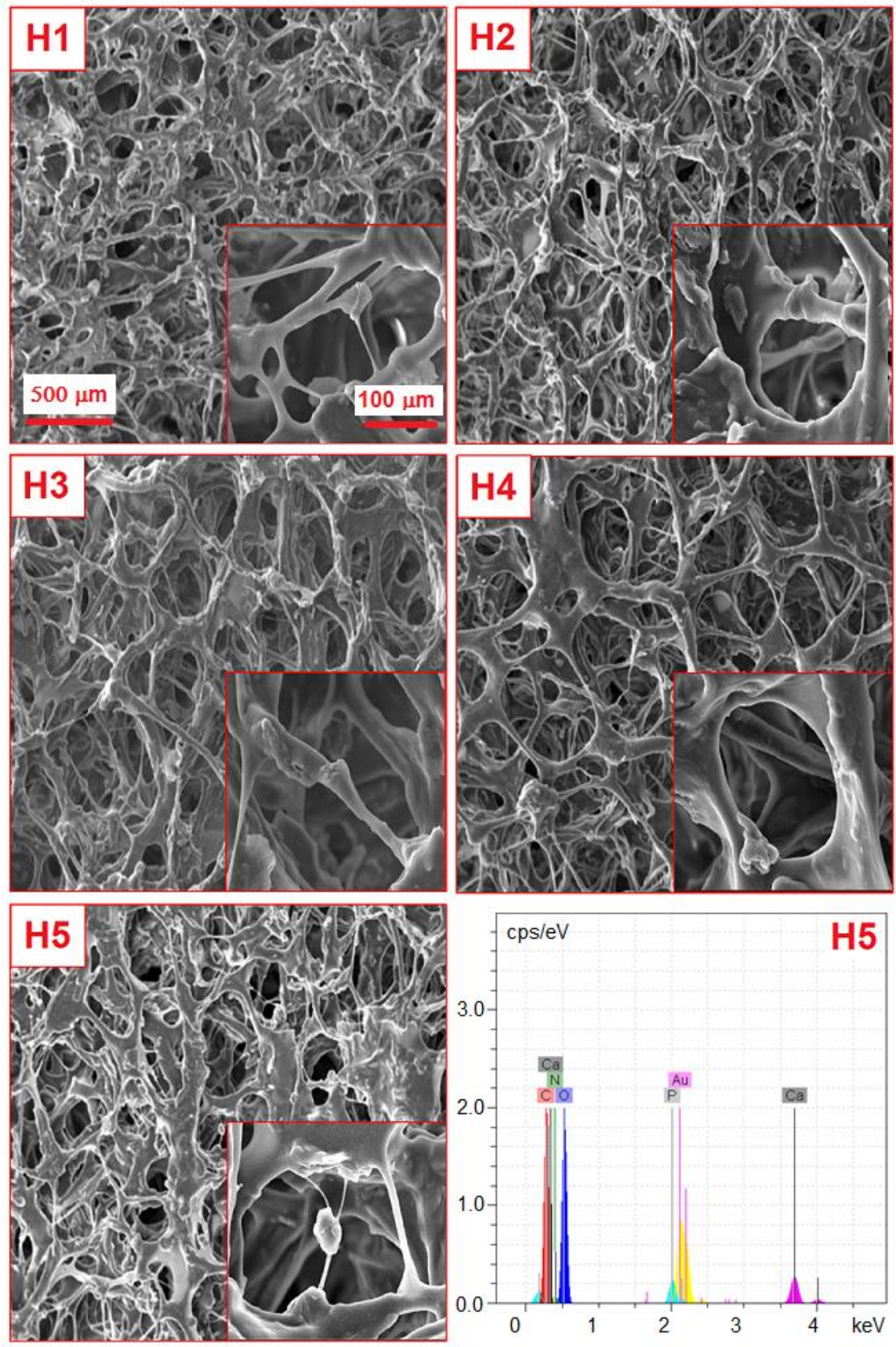

Figure 3 
Table 1. Average pore size, porosity and mechanical properties of the prepared nanocomposite scaffolds

\begin{tabular}{ccccc}
\hline Sample & $\begin{array}{c}\text { Pore size } \\
(\mu \mathrm{m})\end{array}$ & $\begin{array}{c}\text { Porosity } \\
(\%)\end{array}$ & $\begin{array}{c}\text { Compressive strength } \\
(\mathrm{MPa})\end{array}$ & $\begin{array}{c}\text { Elastic modulus } \\
(\mathrm{GPa})\end{array}$ \\
\hline H1 & $125 \pm 4$ & $67.3 \pm 2$ & $1.21 \pm 0.1$ & $0.11 \pm 0.01$ \\
H2 & $110 \pm 5$ & $73.8 \pm 3$ & $3.32 \pm 0.3$ & $0.49 \pm 0.02$ \\
H3 & $94 \pm 2$ & $76.1 \pm 1$ & $5.97 \pm 0.2$ & $0.69 \pm 0.02$ \\
H4 & $83 \pm 2$ & $82.4 \pm 2$ & $1.67 \pm 0.1$ & $0.78 \pm 0.01$ \\
H5 & $72 \pm 3$ & $85.7 \pm 3$ & $1.59 \pm 0.3$ & $0.89 \pm 0.01$ \\
Trabecular bone ${ }^{46,47}$ & $300-600$ & $75-85$ & $2-6$ & $0.1-0.3$ \\
\hline
\end{tabular}

The X-ray emitted from a random place in the wall's pore of the H5 nanocomposite scaffold during bombardment by an electron beam was analyzed, and the EDS spectrum was obtained. Figure 3 displays the main signals for Cel (i.e., carbon and oxygen), AAm (i.e., carbon, oxygen, and nitrogen), and n-HA (i.e., calcium, phosphorus, and oxygen). According to the EDS spectrum, the walls of the pores are composed of HA/Cel-g-PAAm nanocomposites within the scaffolds.

\subsection{Mechanical properties}

When using porous structures for tissue engineering scaffolds, the structure must retain sufficient mechanical properties to fulfill the requirements of structural integrity once implanted in the host tissue $^{42}$. The elastic modulus and compressive strength of the scaffolds were calculated and they are listed in the Table 1. The elastic modulus was the slope of the initial linear portion and the compressive strength was the maximum point of the curve. As shown in Table 1, the elastic modulus of nanocomposite scaffolds was enhanced by increasing the amount of n-HA in samples 
$\mathrm{H} 1$ to $\mathrm{H} 5$ because of the high elastic modulus (an intrinsic property) of ceramics compared with polymers. Although the compressive strength of the scaffolds was expected to increase by increasing the n-HA contents and subsequently increasing the crystallinity of nanocomposite, the results indicated that sample $\mathrm{H} 3$ instead of $\mathrm{H} 5$ had the highest compressive strength. This behavior can be explained by the fact that the compressive strength is affected by the other factors, such as porosity, aside from crystallinity. As, a high porosity causes a decrease in the mechanical strength of porous materials, the $\mathrm{H} 4$ and $\mathrm{H} 5$ nanocomposite scaffolds with the higher porosity than $\mathrm{H} 3$ had a lower compressive strength.

\subsection{Swelling behavior of composite}

As shown in Figure 4, the structural stability of the scaffolds in water and PBS solution, which matches with the human body solution from the perspective of osmolarity and ion concentrations, was evaluated in terms of swelling percentage. When the scaffold immersed in the liquid, the water molecules were in contact with the pores of the scaffold. The osmotic pressure difference between the solution and the scaffold increased. Thus, the scaffold started to uptake water molecules to overcome this difference ${ }^{43}$. The molecules penetrated inside the nanocomposite scaffold network through its pores. Therefore, the high swelling rate was observed at the beginning. Clearly, this swelling system could not continue forever. The osmotic pressure difference between the solution and the scaffold might be reduced by the increasing water scaffold interactions until the equilibrium state was balanced ${ }^{44}$. The results exhibited that the swelling percentage of the scaffolds was inversely proportional to the n-HA concentration in the nanocomposite and that the equilibrium swelling ratio decreased from $\mathrm{H} 1$ to $\mathrm{H} 5$. The result could be due to the low hydrophilicity of n-HA particles compared with that of Cel-g-PAAm. 
Furthermore, the swelling ratio reached equilibrium in the PBS solution more quickly than that in distilled water. The maximum swelling of $\mathrm{H} 1$ in distilled water was $115.8 \%$, which was greater than $69.3 \%$ in the PBS solution. These results can be explained using the role of n-HA as a crosslinker. The existence of n-HA resulted in the generation of ionic interactions with the mono- and multivalent ions in the PBS solution. Thus, it led to the reduced initial osmotic pressure difference between the external solution and the scaffold. Therefore, the swelling capacity of the nanocomposite scaffolds in the PBS solution decreased. 

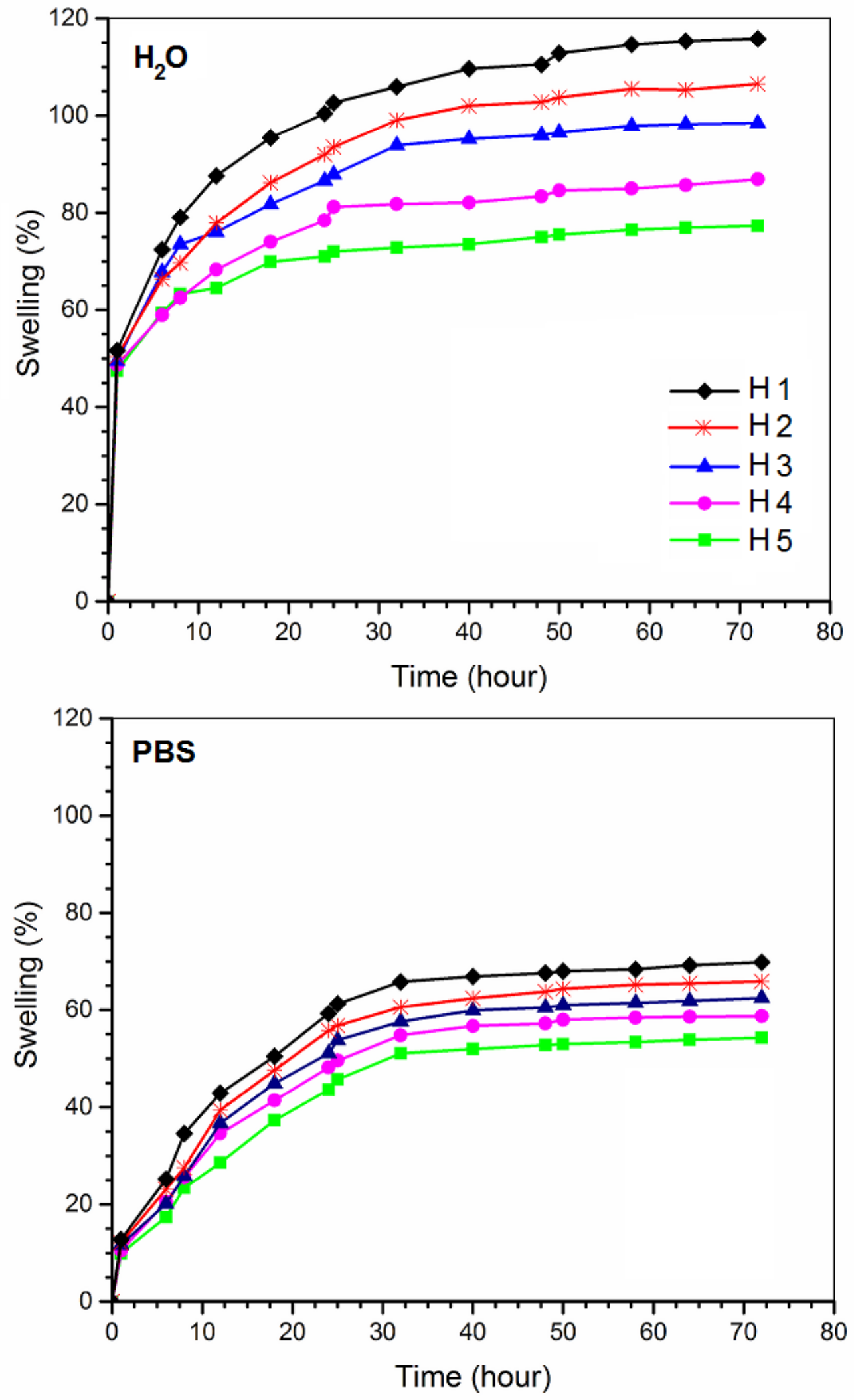

Figure 4 


\subsection{Cytotoxicity of the prepared scaffolds}

Biomaterial cytotoxicity can emanate from the original material itself and from the by-products that may leach out from the material ${ }^{45}$. The cytotoxicity of the seven scaffolds' (H1 and H5) extracts was estimated by evaluating the viability of HuGu cells using an MTT assay. As shown in Figure 5, extracts of both scaffolds with different concentrations have good cell viability, and they were higher than that of the control samples after $72 \mathrm{~h}$ of culturing, thus indicating a higher proliferation rate. From the results of OD and cell viability curves for both scaffolds, the prepared nanocomposite scaffolds with different n-HA contents in the concentration of each exctract is not cytotoxic. In addition, the optical imaging of the HuGu fibroblastic cells in Figure 6 shows that the number of cells increased during the culturing time. After $72 \mathrm{~h}$, the cells were densely arranged and seemed to be pile up on each other. The prepared cytocompatible and nontoxic scaffolds can be concluded to potentially be used in biomedical applications. 

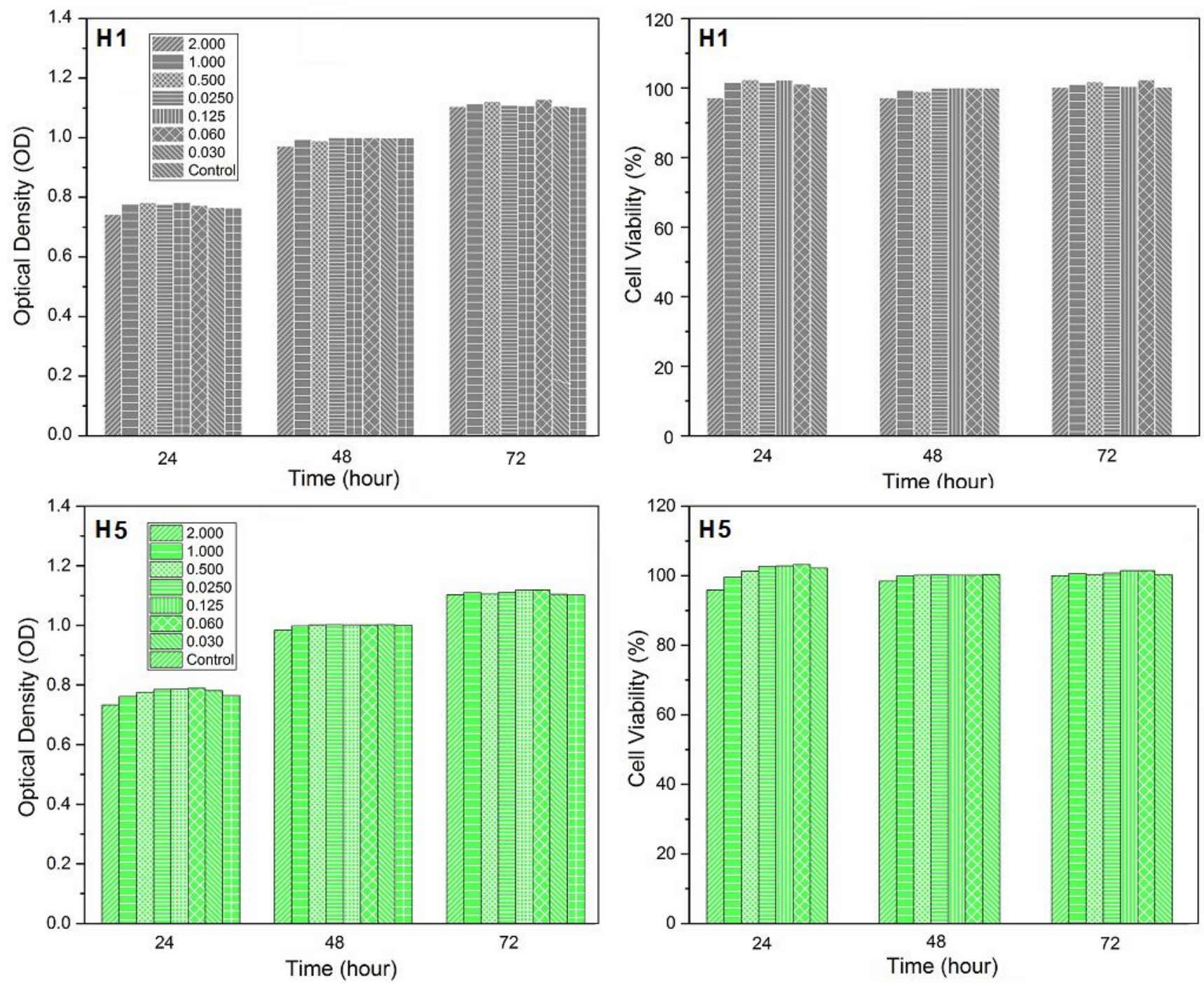

Figure 5 

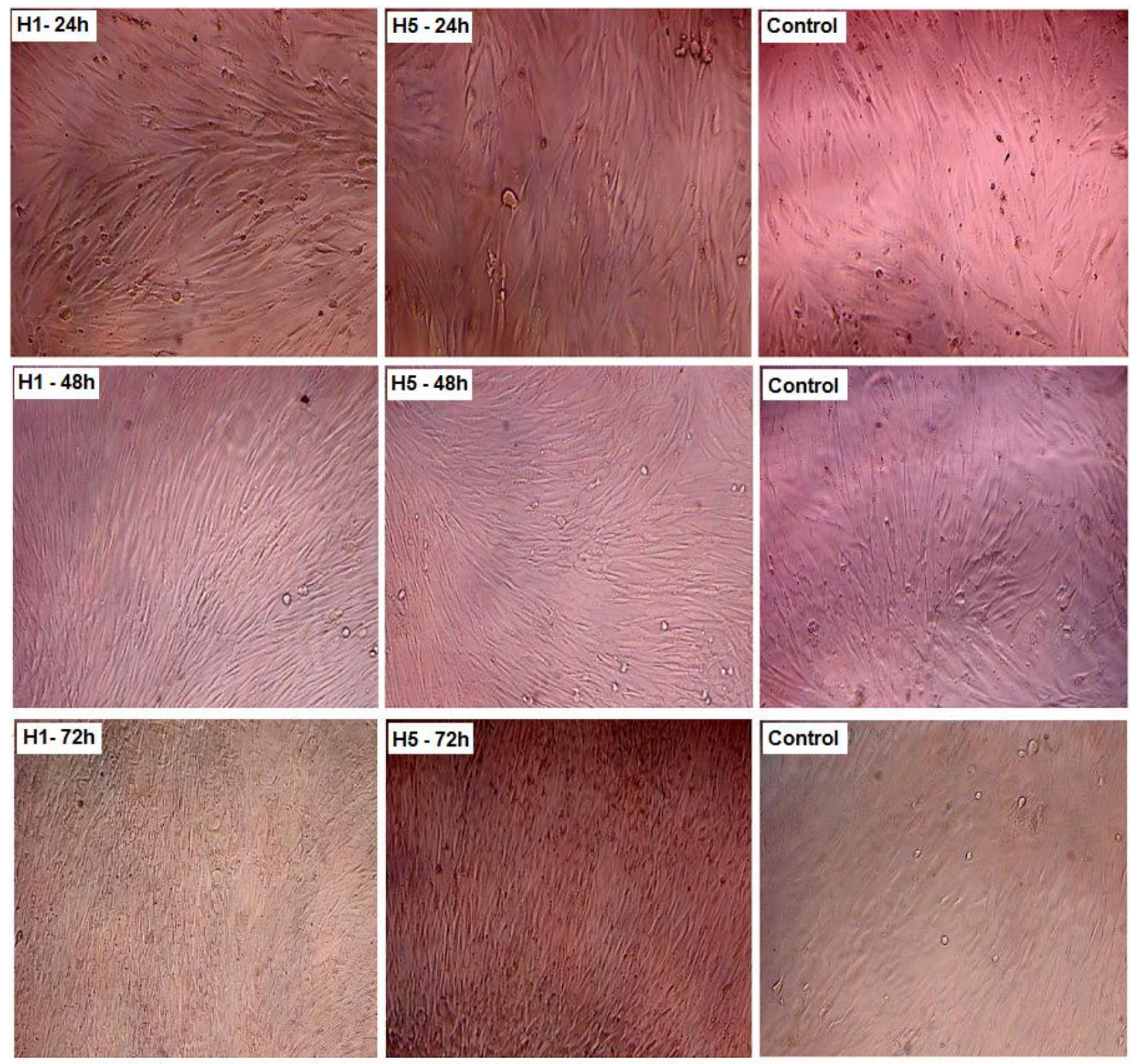

Figure 6

\section{Conclusions}

In summary, by employing the freeze-drying method, HA/Cel-g-PAAm nanocomposite scaffolds were successfully manufactured. Microscopy images demonstrated that these novel scaffolds 
have a porous, interconnected, and rough structure. The results confirmed that by increasing the n-HA amounts in the structure of scaffolds, pore size decreased from $125 \mu \mathrm{m}$ to $72 \mu \mathrm{m}$, while porosity increased from $67.3 \%$ to $85.7 \%$. Structural analysis results showed that n-HA powders were uniformly dispersed and successfully incorporated into the Cel-g-PAAm matrix. Compared with the trabecular bone, the n-HA/Cel-g-PAAm scaffolds showed close mechanical strength, which could be controlled by varying the amount of n-HA. HuGu cells cultured in the n-HA/Celg-PAAm scaffolds showed that the scaffolds are non-toxic and have good biocompatibility. Based on our observations, the introduced novel scaffolds are considered a promising candidate for bone tissue engineering application. 


\section{References}

1. Braddock $M$, Houston $P$, Campbell C, Ashcroft P. Born again bone: tissue engineering for bone repair. Am. Physiol. Soc. 2001;16:208-213.

2. Tsai ST, Hsu FY, Chen PL. Beads of collagen-nanohydroxyapatite composites prepared by a biomimetic process and the effects of their surface texture on cellular behavior in MG63 osteoblast-like cells. Acta Biomater. 2008;4:1332-1341.

3. Uemura T, Dong J, Wang Y, Kojima H, Saito T, lejima D, Kikuchi M, Tanaka J, Tateishi T. Transplantation of cultured bone cells using combinations of scaffolds and culture techniques. Biomaterials 2003;24:2277-2286.

4. Meyer U, Joos U, Wiesmann HP. Biological and biophysical principles in extracorporal bone tissue engineering: Part III. Int. J. Oral Maxillofac. Surg. 2004;33:635-641.

5. Freyman T, Yannas I, Gibson L. Cellular materials as porous scaffolds for tissue engineering. Prog. Mater. Sci. 2001;46:273-282.

6. Pon-On W, Suntornsaratoon P, Charoenphandhu N, Thongbunchoo J, Krishnamra N, Tang IM. Hydroxyapatite from fish scale for potential use as bone scaffold or regenerative material. Mater. Sci. Eng. C 2016;62:183-189.

7. Zhou XH, Wei DX, Ye HM, Zhang X, Meng X, Zhou Q. Development of poly(vinyl alcohol) porous scaffold with high strength and well ciprofloxacin release efficiency. Mater. Sci. Eng., $C$ 2016;67:326-335.

8. Fereshteh Z, Fathi M, Bagri A, Boccaccini AR, Preparation and characterization of aligned porous $\mathrm{PCL} / z e i n$ scaffolds as drug delivery systems via improved unidirectional freeze-drying method. Mater. Sci. Eng., C 2016;68:613-622.

9. Zhao W, Li J, Jin K, Liu W, Qiu X, Li C. Fabrication of functional PLGA-based electrospun scaffolds and their applications in biomedical engineering. Mater. Sci. Eng. C 2016;59:1181-1194.

10. Saravanan S, Sameera DK, Moorthi A, Selvamurugan N. Chitosan scaffolds containing chicken feather keratin nanoparticles for bone tissue engineering. Int. J. Biolog. Macromol. 2013;62:431486.

11. de Araújo Júnior AM, Braido G, Saska S, Barud HS, Franchi LP, Assunção RMN, Scarel-Caminaga RM, Capote TSO, Messaddeq Y, Ribeiro SJL. Regenerated cellulose scaffolds: Preparation, characterization and toxicological evaluation. Carbohyd. Polym. 2016;136:892-898.

12. Kruppke B, Farack J, Wagner AS, Beckmann S, Heinemann C, Glenske K, Rößler S, Wiesmann HP, Wenisch S, Hanke T. Gelatine modified monetite as a bone substitute material: An in vitro assessment of bone biocompatibility. Acta Biomater. 2016;32:275-285.

13. Langer R, Vacanti JP. Tissue engineering. Science 1993;260:920-926.

14. Ma PX, Zhang R, Xiao G, Franceschi R. Engineering new bone tissue in vitro on highly porous poly(alpha-hydroxyl acids)/hydroxyapatite composite scaffolds. J. Biomed. Mater. Res. 2001;54:284-293.

15. Peter M, Binulal NS, Nair SV, Selvamurugan N, Tamura H, Jayakumar R. Novel biodegradable chitosan-gelatin/nano-bioactive glass ceramic composite scaffolds for alveolar bone tissue engineering. Chem Eng. J. 2010;158:353-361.

16. Saber-Samandari S, Alamara K, Saber-Samandari S. Calcium phosphate coatings: Morphology, micro-structure and mechanical properties. Ceram. Int. 2014;40 563-572.

17. LeGeros RZ. Properties of osteoconductive biomaterials: calcium phosphates. Clin. Orthop. Relat. Res. 2002;395:81-98.

18. Saber-Samandari S, Nezafati N, Saber-Samandari S. The effective role of hydroxyapatite based composites in anticancer drug delivery systems. Crit. Rev. Ther. Drug. Carrier Syst. 2016;33:4175. 
19. Li L, Zhao M, Li J, Zuo Y, Zuo Q, Li Y. Preparation and cell infiltration of lotustype porous nanohydroxyapatite/polyurethane scaffold for bone tissue regeneration Mater. Lett. 2015;149:25-28.

20. Pohunkova $\mathrm{H}$, Adam M. Reactivity and the fate of some composite bioimplants based on collagen in connective tissue. Biomaterials 1995;16:67-71.

21. Cooke FW. Ceramics in orthopedic surgery. Clin. Orthop. Relat. Res. 1992;276:135-146.

22. Yamaguchi K, Prabakaran M, Ke M, Gang X, Chung M, Chul Um I, Gopiraman M, Soo Kim I. Highly dispersed nanoscale hydroxyapatite on cellulose nanofibers for bone regeneration. Mater. Lett. 2016;168:56-61.

23. S.C. Chao, M.J. Wang, N.S. Pai, S.K. Yen. Preparation and characterization of gelatinhydroxyapatite composite microspheres for hard tissue repair. Mater. Sci. Eng., C 2015;57:113122.

24. Tsioptsias C, Tsivintzelis I, Papadopoulou L, Panayiotou C. A novel method for producing tissue engineering scaffolds from chitin, chitin-hydroxyapatite, and cellulose. Mater. Sci. Eng. C 2009;29:159-164.

25. Saber-Samandari S, Saber-Samandari S, Gazi M, Cebeci FC, Talasaz E. Synthesis, characterization and application of cellulose based nano-biocomposite hydrogels. J. Macromol. Sci. Pure Appl. Chem. 2013;50:1133-1141.

26. Zhou C, Wu Q. A novel polyacrylamide nanocomposite hydrogel reinforced with natural chitosan nanofiber. Colloids Surf. B. 2011;84:155-162.

27. Li Z, Mi W, Wang H, Su Y, He C. Nano-hydroxyapatite/polyacrylamide composite hydrogels with high mechanical strengths and cell adhesion properties. Colloids Surf. B. 2014:959-964.

28. Calvert P. Hydrogels for soft machines. Adv. Mater. 2009;21:743-756.

29. Drury JL, Mooney DJ. Hydrogels for tissue engineering: scaffold design variables and applications. Biomaterials 2003;24:4337-4351.

30. Lin DC, Yurke B, Langrana NA. Mechanical properties of a reversible, DNA-crosslinked polyacrylamide hydrogel. J. Biomech. Eng. 2004;126:104-110.

31. Hynd MR, Turner JN, Shain W. Applications of hydrogels for neural cell engineering. J. Biomater. Sci. Polym. Ed. 2007;18:1223-1244.

32. Brown HR. A model of the fracture of double network gels. Macromol. 2007;40:3815-3818.

33. Cohen Y, Ramon O, Kopelman IJ, Mizrahi S. Characterization of inhomogeneous polyacrylamide hydrogels. J. Polym. Sci. B. 1992;30:1055-1067.

34. Saber-Samandari S, Saber-Samandari S, Kiyazar S, Aghazadeh J, Sadeghi A. In vitro evaluation for apatite-forming ability of cellulose-based nanocomposite scaffolds for bone tissue engineering. Int. J. Biolog. Macromol. 2016;86:434-442.

35. Archana D, Upadhyay L, Tewari RP, Dutta J, Huang YB, Dutta PK. Chitosan-pectin-alginate as a novel scaffold for tissue engineering applications. Indian J. Biotechnol. 2013;12:475-482.

36. Saber-Samandari S, Gazi M, Yilmaz O. Synthesis and characterization of chitosan-graft-poly(nallyl maleamic acid) hydrogel membrane. Water Air Soil Pollut. 2013;224:1624.

37. Zhu W, Zhao W, Zheng X, Zhang Z, Jiang T, Li Y, Wang S. Mesoporous carbon as a carrier for celecoxib: The improved inhibition effect on MDA-MB-231 cells migration and invasion Asian J. Pharm. Sci. 2014;9:82-91.

38. Saber-Samandari S, Saber-Samandari S, Ghonjizade-Samani F, Aghazadeh J, Sadeghi A. Bioactivity evaluation of novel nanocomposite scaffolds for bone tissue engineering: The impact of hydroxyapatite. Ceram. Int. 2016;42 11055-11062.

39. Ulian G, Valdre G, Corno M, Ugliengo P. The vibrational features of hydroxylapatite and type A carbonated apatite: A first principle contribution. Am. Mineral. 2013;98:752-759. 
40. Saber-Samandari S, Alamara K, Saber-Samandari S, Gross KA. Micro-Raman spectroscopy shows how the coating process affects the characteristics of hydroxylapatite. Acta Biomater. 2013;9:9538-9546.

41. Mancini CE, Berndt CC, Sun L, Kucuk A. Porosity determinations in thermally sprayed hydroxyapatite coatings. J. Mater. Sci. 2001;36:3891-3896.

42. Sabree I, Gough JE, Derby B. Mechanical properties of porous ceramic scaffolds: Influence of internal dimensions. Ceram. Int. 2015;41:8425-8432.

43. Saber-Samandari S, Yilmaz O, Yilmaz E. Photoinduced graft copolymerization onto chitosan under heterogeneous conditions. J. Macromol. Sci. A 2012;49:591-598.

44. Saber-Samandari S, Gulcan HO, Saber-Samandari S, Gazi M. Efficient removal of anionic and cationic dyes from an aqueous solution using pullulan-graft-polyacrylamide porous hydrogel. Water Air Soil Pollut. 2014;225:2177.

45. Changotade C, Bostan GR, Consalus A, Poirier F, Peltzer J, Lataillade JJ, Lutomski D, Rohman G. Preliminary in vitro assessment of stem cell compatibility with cross-linked poly( $\varepsilon$-caprolactone urethane) scaffolds designed through high internal phase emulsions. Stem Cells Int. 2015;2015:283796.

46. Lee S, Porter M, Wasko S, Lau G, Chen PY, Novitskaya EE, To msia AP, Almutairi A, Meyers MA, McKittrick J. Potential bone replacement materials prepared by two methods. Mater. Res. Soc. Symp. Proc. 2012;1418 177- 181.

47. Chen PY, McKittrick J. Compressive mechanical properties of demineralized and deproteinized cancellous bone. J. Mech. Behav. Biomed. Mater. 2011;4:961-973. 


\section{Figure captions}

Scheme 1. The schematic illustration for the preparation of scaffold

Fig. 1 The peaks in FTIR spectra of the prepared nanocomposite scaffolds (H1-H5) in the range of $400-4000 \mathrm{~cm}^{-1}$

Fig. 2 The XRD patterns of the prepared nanocomposite scaffolds (H1-H5)

Fig. 3 The SEM images of the prepared nanocomposite scaffolds. EDS point analysis for elemental composition of the prepared nanocomposite scaffold (H5)

Fig. 4 The swelling behavior of the prepared nanocomposite scaffolds (H1-H5) in distilled water and PBS solution

Fig. 5 MTT assay of HUGU cells for the scaffolds (H1 and H5) extracts in terms of optical density values and the normalized cell viability (\%) after 24, 48, and $72 \mathrm{~h}$.

Fig. 6 Optical images of the cell morphology in the presence of the scaffolds (H1 and H5) extracts after 24,48 , and $72 \mathrm{~h}$. 


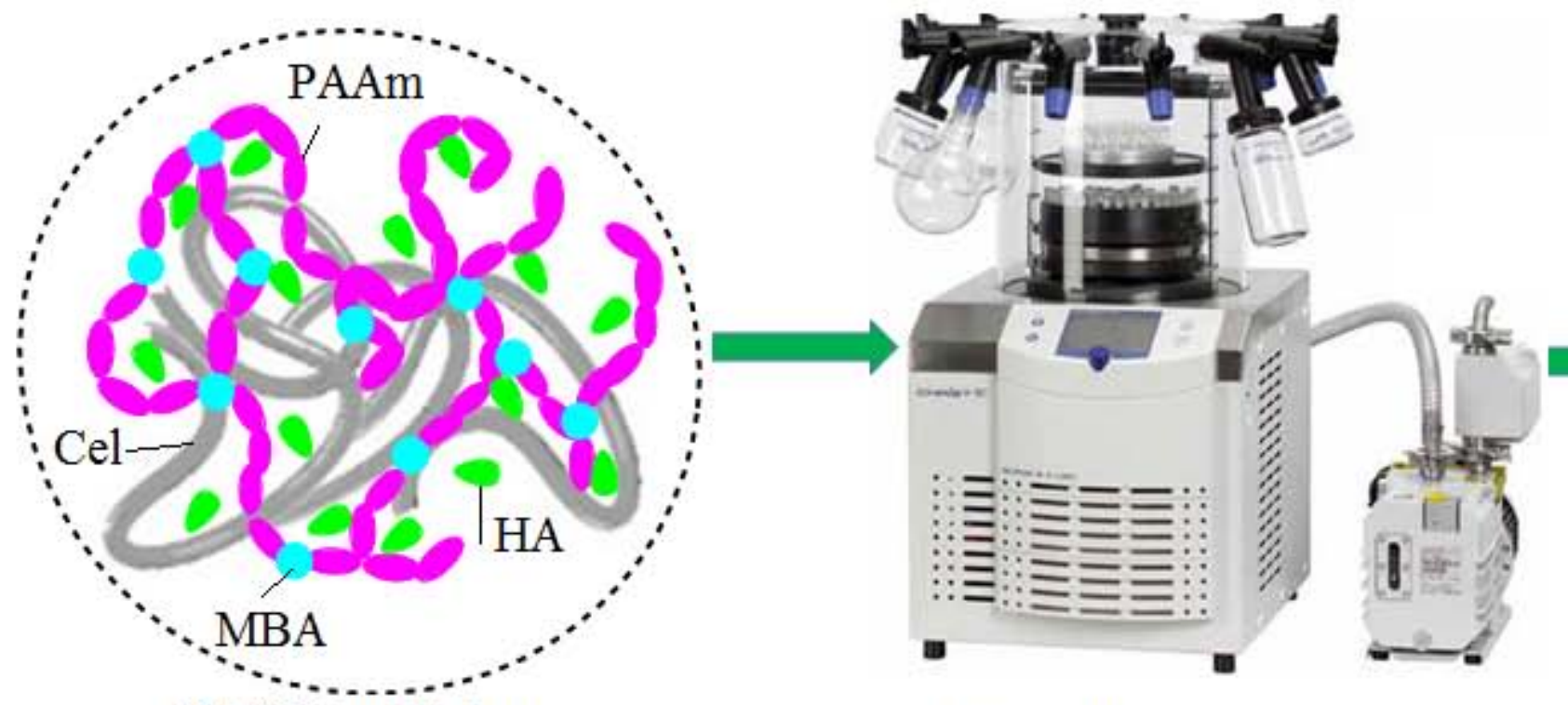

HA/Cel-g-PAAm nanocomposite powder
Freeze dryer

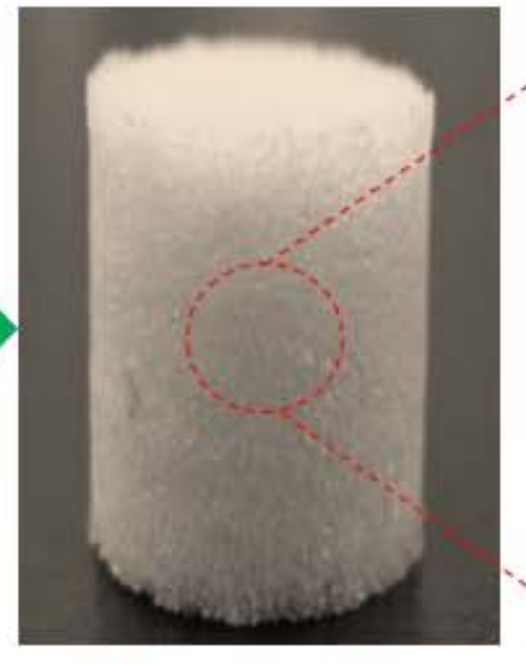

$\mathrm{HA} / \mathrm{Cel}$-g-PAAm nanocomposite scaffold

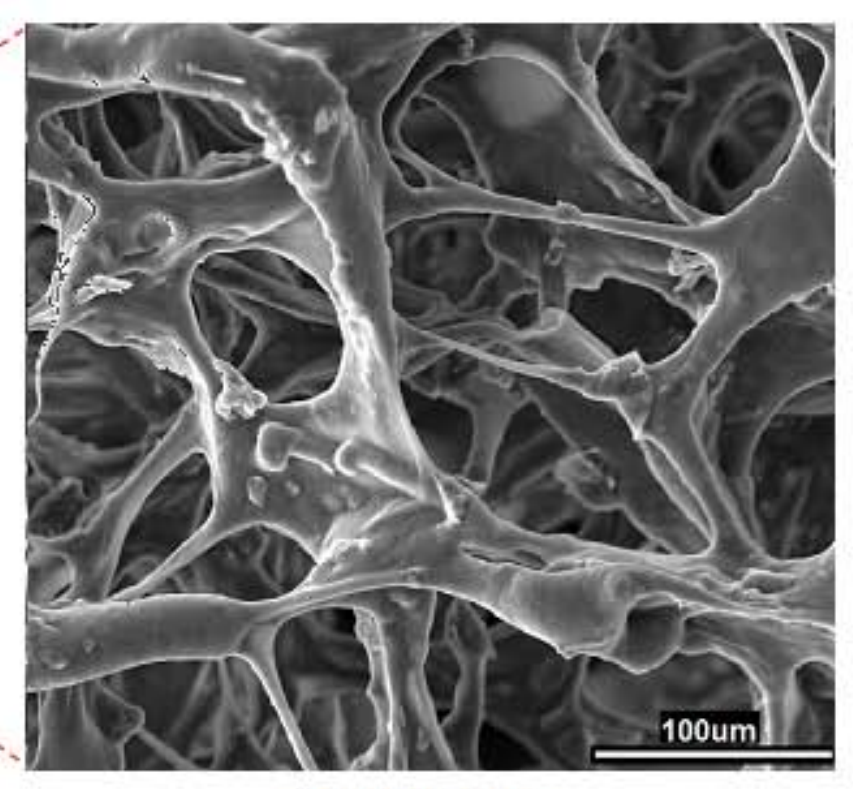

SEM image 